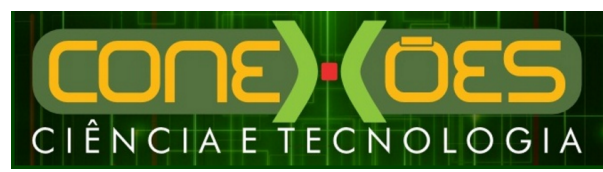

ANÁLISE DA INADIMPLÊNCIA BANCÁRIA: UM ESTUDO DE CASO DA REGIÃO METROPOLITANA DE FORTALEZA

\title{
ANÁLISE DA INADIMPLÊNCIA BANCÁRIA: UM ESTUDO DE CASO DA REGIÃO METROPOLITANA DE FORTALEZA
}

\author{
Harine Matos Maciel e Wlisses Matos Maciel \\ Instituto Federal de Educação, Ciência e Tecnologia do Ceará (IFCE) \\ <harinematos@yahoo.com.br>, <wlissesmatos@yahoo.com.br>
}

DOI: 10.21439/conexoes.v11i3.867

\begin{abstract}
Resumo. A concessão de crédito tornou-se uma das principais operações dos bancos pós-estabilização econômica. O setor bancário busca uma melhoria na análise de concessão de crédito, pois existe o risco das pessoas não honrarem seu compromisso com a instituição financeira. É fundamental que haja um acompanhamento das operações para garantir o retorno dos empréstimos concedidos. Desta forma, o objetivo do trabalho foi analisar os principais fatores que determinam a inadimplência de clientes de um banco comercial em um município da região metropolitana de Fortaleza. Para analisar a probabilidade de inadimplência do cliente, foi construído um modelo com o objetivo de identificar relações significantes entre a variável dependente (probabilidade de inadimplência) e as variáveis explicativas (estado civil, tempo de conta, grau de instrução, idade, sexo e renda). Os principais resultados obtidos foram que ambos os sexos possuem participações semelhantes no setor bancário, a idade média dos clientes é de 47 anos, a escolaridade concentra-se no ensino médio e superior completo, a renda de mais de $50 \%$ dos clientes é maior ou igual a cinco salários mínimos e 66,78\% dos clientes da agência estudada estão adimplentes. Para analisar a probabilidade de inadimplência do cliente, foi construído um modelo com o objetivo de identificar relações significantes entre a probabilidade de inadimplência e o estado civil, tempo de conta, grau de instrução, idade, sexo e renda. Os coeficientes que mais influenciaram a probabilidade de inadimplência foram os das variáveis: tempo de conta, idade, grau de instrução e renda. Os resultados demonstraram não haver relações significantes entre todas as variáveis estudadas. Apesar disso, acredita-se que os resultados deste trabalho devem ser aprofundados através de estudos posteriores para tornar possíveis conclusões definitivas quanto à relação entre as principais variáveis utilizadas na gerência de risco de um cliente bancário.
\end{abstract}

Palavras-chaves: Crédito. Banco. Risco. Inadimplência. Clientes.

Abstract. The granting of credit has become one of the main operations of economic poststabilization banks. The banking industry seeking an improvement in the credit granting analysis because there is a risk of people not honoring its commitment to the financial institution. It is essential that there be a follow-up operations to ensure the return of the loans. Thus, the aim of this study was to analyze the main factors that determine customer default of a commercial bank in a city of the metropolitan region of Fortaleza. The main results were that both sexes have similar interests in banking, the average age of clients is 47 years, the school focuses on medium and complete higher education, income of more than $50 \%$ of customers is greater than or equal to five minimum wages and $66.78 \%$ of the studied agency's clients are compliant. To analyze the probability of customer default, it built a model in order to identify significant relationships between the probability of default and marital status, account time, level of education, age, gender and income. The coefficients that most influenced the probability of default were the variables: Account of time, age, education level and income. The results showed no significant relationships between all variables. Nevertheless, it is believed that the results of this work should be investigated by further studies possible to make definitive conclusions regarding the relationship between the main variables used in the risk management of a bank customer.

Keywords: Credit. Bank. Risk. Default. Customers. 


\section{INTRODUÇÃO}

A concessão de crédito consiste na disponibilidade de valores mediante a uma promessa de pagamento desse mesmo valor acrescido de encargos no futuro. Esta é a principal atividade desenvolvida pelos bancos e de acordo com Cihák (2007) representa o principal risco a que estão expostos.

Um objetivo importante do setor bancário é a melhoria das análises de concessão de crédito, pois o risco de crédito ocorre quando pessoas não honram seu compromisso com a instituição financeira. Para isso os analistas de crédito precisam estar atualizados com o mercado financeiro mundial, pois as decisões de crédito dependem principalmente da análise da capacidade de pagamento dos tomadores de recursos financeiros.

De acordo com Lanari e Junios (2000) a classificação do risco de crédito tem como objetivo atribuir aos tomadores do crédito uma nota que reflita o seu risco de inadimplência, bem como os impactos que essa inadimplência pode causar nos fornecedores do crédito. Resumidamente a classificação de crédito procura melhorar a gestão do risco de crédito bancário.

O setor bancário lucra com a concessão de crédito, mas em contrapartida correm riscos e por isso cobram altas taxas de juros. Segundo a FEBRABAN (2009) apud Rocha (2010), o principal motivo das altas taxas de juros cobrados no sistema bancário é a inadimplência. Devido a isso é necessário que as instituições financeiras possuam um gerenciamento de risco para assegurar que o total de risco assumido é comparável à capacidade que o banco tem de absorver perdas potenciais em caso de falta de pagamento.

A investigação da origem de créditos inadimplentes é importante, pois bancos com baixos níveis de inadimplência possuem menor probabilidade de falência. Segundo Chang et al. (2008) o aumento da inadimplência provoca uma redução da lucratividade dos bancos e da atividade econômica em virtude da restrição à concessão de novos empréstimos.

A política expansionista de crédito que o Brasil adotou nos últimos anos auxilia o crescimento econômico, pois sem recursos financeiros não se produz e nem se consome como o esperado. Porém estudiosos como Maia (2007), Mendes (2013) e (SBICCA; FLORIANI; JUK 2012) demonstram preocupação com essa expansão, pois futuramente poderá haver um estrangulamento na oferta de produtos e uma explosão de consumo, causando uma pressão inflacionária. O importante nesta situação é manter uma boa administração da política monetária e fiscal.

Os bancos devem ser responsáveis na concessão de crédito, buscando acompanhar de forma minuciosa as operações para que os níveis de inadimplência não aumentem e para que seus resultados não sejam afetados negativamente e consequentemente o sistema financeiro nacional por completo.

Este trabalho teve como principal objetivo analisar os principais fatores que determinam à inadimplência dos tomadores de crédito em um município da região metropolitana de Fortaleza.

\section{JUSTIFICATIVA}

Com a estabilização econômica ocorrida em julho de 1994, houve modificações consideráveis para o sistema financeiro brasileiro, pois os bancos deixariam de ganhar com a inflação. Ao perderem esta vantagem financeira os bancos reduziram sua estrutura de captação e adaptaram uma estratégia operacional para recompor a perda de lucratividade, expandindo assim as operações de crédito.

O período pós-inflacionário pode ser dividido em dois momentos. O primeiro caracterizado pelo otimismo dos agentes econômicos que, acostumados a atuarem em um contexto de instabilidade de preços, passaram a vivenciar um momento de equilíbrio e assim, criando fortes expectativas para demandar mais crédito e as instituições financeiras dispostas a ofertar e cobrir esta demanda, já que a principal fonte de receita oriunda da inflação tinha acabado. Porém, no segundo momento, a história segue outro rumo, caracterizado pelo aumento do nível da inadimplência (GONÇALVES, 2007).

Inadimplência bancária é o não recebimento de créditos rotativos utilizados pelas pessoas físicas ou jurídicas. A inadimplência surge com a expansão do crédito e o incentivo cada vez maior ao consumo. É fundamental que haja acompanhamento das operações para que se possa garantir ao máximo o retorno dos empréstimos concedidos.

Bons créditos podem se tornar inadimplidos e eventualmente se converterem em prejuízos, caso o analista de crédito não acompanhe, não identifique e não tome ações corretivas no momento oportuno aos sinais de alerta, que possam vir a impactar os repagamentos das operações de crédito previamente aprovadas (BLATT. 1999).

O risco de inadimplência está presente em todas as operações que envolvem crédito, porém esse risco pode ser minimizado com o rigoroso cumprimento dos prérequisitos que envolvem a obtenção e a liberação de tais créditos. No combate à inadimplência a atuação de profissionais especializados na gestão do risco tem importância fundamental. 
Segundo a revista Exame (2009) apud Rocha (2010), "a crise mundial, que afetou o Brasil mais fortemente a partir de Setembro/2008 teve fortes consequências sob as políticas de concessão de crédito. Com o coração do sistema financeiro em crise - os EUA, os outros países também foram afetados".

No Brasil a contração de crédito foi bem passageira como mostram dados da Federação Brasileira de Bancos FEBRABAN (2009) em Junho apud Rocha (2010), "o saldo de operações de crédito foi de R\$ 1.278 trilhões, o que equivale a 43,7 do Produto Interno Bruto (PIB), com relação ao mês de maio/2009 houve incremento de $1,3 \%$ e a comparação com o mesmo período do ano anterior o aumento foi de 19,7\%". E ainda de acordo com o Brasil (2011) houve nos últimos 12 meses uma elevação de $20,3 \%$ nos estoques de empréstimos, mas essa expansão do crédito veio aliada com o aumento da inadimplência.

O crédito inadimplente representa as operações de crédito vencidas a mais de 90 dias. Segundo a empresa de consultoria de crédito CERASA (2011) a inadimplência dos consumidores brasileiros cresceu 24,8\% em janeiro deste ano, em relação ao mesmo mês do ano passado. Este é o maior aumento anual desde julho de 2002 e ocorreu devido à expansão do endividamento da população no ano de 2010.

O crédito é fundamental para o crescimento da economia porque fomenta a produção, emprego e o consumo, mas é necessário ser controlado, pois essa facilidade de contrair empréstimos faz com que a população ultrapasse sua capacidade de pagamento, aumentando assim o nível de inadimplência.

O tema deste trabalho é justificado pela importância dos últimos anos da gestão de riscos das operações financeiras, já que os bancos possuem a incerteza quanto a capacidade de pagamento dos clientes e com isso necessitam buscar novas alternativas para se proteger de perdas, que podem refletir em menores lucros. O ideal é gerir eficientemente o risco do negócio e para isso está sendo muito utilizado modelos de avaliação de risco de crédito baseados em técnicas estatísticas, auxiliando os gestores a tomarem a decisão de conceder ou não o crédito, minimizando assim o risco de perda.

Diante do exposto, torna-se relevante uma análise dos determinantes de inadimplência dos tomadores de crédito em um banco comercial do estado do Ceará.

\section{REVISÃO BIBLIOGRÁFICA}

\section{Crédito}

Crédito envolve a expectativa do recebimento de um valor em um certo período de tempo. Segundo Schrickel (1997) "crédito é todo ato de vontade de alguém ceder, temporariamente, parte do seu patrimônio a um terceiro, com a expectativa de que esta parcela volte a sua posse integralmente depois de decorrido o tempo estipulado".

A intermediação financeira é a principal atividade dos bancos, mas isso não quer dizer que o conceito de crédito se limite ao setor bancário. Qualquer atividade que possua o crédito como facilitador, este será parte integrante de seu negócio.

$\mathrm{O}$ crédito faz com que as empresas aumentem seu nível de atividade e estimulem o consumo, fazendo a economia girar (compra e venda de bens e serviços) e o país a crescer. Sendo importante ressaltar que o crédito também faz com que as pessoas tornem-se endividadas por não saberem controlar o dinheiro conseguido, por isso é fundamental uma boa análise de crédito.

A análise de crédito consiste na avaliação de todas as informações disponíveis a respeito de um tomador de crédito, que pode ser pessoa física ou jurídica, com o objetivo de decidir sobre a concessão ou não de crédito.

O principal objetivo da análise de crédito é identificar os riscos nas situações de empréstimo. Dentro da análise de crédito o chamado limite de crédito ou limite de risco é um fator importante, já que se trata de um valor indicativo tomado como referencial para o deferimento do crédito.

A tarefa de análise de crédito consiste em analisar o solicitante, a fim de constatar se a instituição financeira aprovara ou não o crédito solicitado e, se positivo, qual o montante a ser liberado. Para a análise, o especialista adiciona toda documentação que servirá como embasamento técnico para o parecer final. Dentre as informações disponíveis podemos destacar o formulário da agência com proposta de crédito e pareceres; comprovante de renda e o questionário de avaliação do cliente.

No processo de análise de crédito é importante que os instrumentos envolvidos para a decisão do crédito sejam adequados a dar agilidade (competitividade) e retomo normal (resultado) das aplicações no prazo e condições acordadas, e dentro dos padrões de qualidade delineados pela instituição.

Já a política de crédito orienta as decisões de crédito, considerando os objetivos desejados e estabelecidos pelas organizações. Os principais componentes de uma política de crédito são: normas legais, definição estratégica do banco, os objetivos a serem alcançados, a forma de decisão e de delegação de poder, os limites de crédito, a análise de crédito, a composição e a formalização dos processos, a administração e o controle de crédito (SILVA, 1998).

\section{Risco e Inadimplência}

A inadimplência ocorre quando a pessoa não honra 
seus compromissos financeiros. De acordo com Silva (1998, p.134) créditos inadimplentes são “aqueles que apresentam dificuldades de serem recebidos e consequentemente acarretam perdas para o credor".

Ter clientes inadimplentes é um risco que os bancos correm ao conceder empréstimos. Risco são todos os eventos que podem ocorrer em um determinado intervalo de tempo: desde o depósito pelo investidor e sua restituição ao depositante. Nesse intervalo de tempo ocorre a aplicação dos recursos pela instituição que, em princípio, depende do recebimento dos recursos aplicados para restituí-los ao depositante.

Os riscos bancários podem ser classificados em:

a) Risco de liquidez: é o tipo mais comum de risco. Relaciona-se com o descasamento de fluxos financeiros ativos e passivos e seus reflexos sobre a capacidade financeira da instituição em obter ativos e honrar suas obrigações.

b) Risco de mercado: relaciona-se a prejuízos potenciais decorrentes de mudanças em fatores de risco como taxas de juros e de câmbio, índices e preços. Trata-se de um risco intimamente ligado com a internacionalização e aumento de complexidade dos mercados, já que tais fatores aumentam a sua volatilidade e potencializam possíveis desequilíbrios.

c) Risco de crédito: está associado às perdas que o credor possa ter ao fornecer crédito a um devedor inadimplente, que não honre seus compromissos na data ajustada. O Banco Central criou em 1997, por meio da Resolução n. 2.390, substituída posteriormente pela Resolução 2.724 de 2000, a Central de Risco de Crédito do Banco Central do Brasil (CRC - Bacen), visando o aprimoramento da capacidade de monitoramento dos riscos de crédito, prevendo crises, detectando eventuais problemas e fornecendo subsídios para a análise e pesquisa do mercado de crédito.

d) Risco operacional: é o risco que uma empresa corre de ser prejudicada por falhas internas do sistema ou de funcionários, ou por um evento externo. Trata-se de um risco de várias modalidades: fraudes, erros, falhas de controles, tecnologias mal utilizadas, além dos já mencionados eventos externos. Por eventos externos, podemos citar como exemplo, não sem ressalvas, a responsabilidade por assaltos dentro de agências.

e) Risco regulatório ou legal: ocorre quando as mudanças de legislação ou regulamentação das atividades das instituições financeiras provocam oscilações inesperadas para mais ou para menos em valores de ativos ou passivos. Trata-se de um risco diretamente ligado ao Banco Central e ao Conselho Monetário Nacional, que devem se precaver de todas as formas antes de promoverem alterações na política do Sistema Financeiro Nacional.

f) Risco moral: corresponde ao comportamento do agente econômico de assumir mais riscos, tanto quanto maior for o aparato de proteção. O Banco Central (Bacen) é o responsável pela prevenção deste risco bancário. Embora possa injetar recursos, cabe ao Bacen analisar a viabilidade do empréstimo a instituições financeiras em crise, a fim de evitar a incidência do risco moral.

g) Risco sistêmico: ocorre quando a instituição financeira não possui recursos suficientes e deixa de pagar outra, causando o chamado efeito dominó, levando ao colapso todo o sistema financeiro.

As instituições financeiras buscam uma maior proteção em relação à concessão de crédito através de serviços que disponibilizam informações sobre clientes inadimplentes (SPC - Serviço de Proteção ao Crédito e SERASA). Outra forma de proteção é a Provisão para Crédito de Liquidação Duvidosa (PCLD) que tem o objetivo de sensibilizar contabilmente a conta de resultado, assim traz para o presente as previsões de perdas com a carteira de crédito, possibilitando prever o impacto no resultado.

Segundo Lucca () a inadimplência prejudica credores e devedores, pois quando os bancos não recebem o valor que foi emprestado aos inadimplentes, quem arca com esses prejuízos são os outros tomadores, já que os bancos incorporam na taxa de juros o risco de inadimplência.

É importante o acompanhamento das operações de crédito concedidas para minimizar a inadimplência, assim evita-se o custo que se tem para cobrar a operação e o custo de não se receber os valores emprestados.

De acordo com Pirolo (2003, p.65) "recuperar crédito é a missão mais árdua de qualquer instituição financeira, principalmente quando essa instituição está nos limites da inadimplência resultantes do não recebimento dos créditos".

Através da negociação o banco procura aproximarse mais do cliente permitindo que sejam criados vínculos duradouros. O objetivo da negociação é saber até onde o cliente pode ir. Para que o processo de cobrança e recuperação de crédito ocorra com êxito é necessário que o cadastro dos clientes esteja atualizado e com o máximo de informações possíveis, principalmente às que dizem respeito à localização desses clientes como telefones e endereços. 
Na telecobrança é imprescindível a negociação para se alcançar a máxima eficiência. Ele apresenta dois tipos de ações utilizadas na telecobrança, são elas: "teleaviso de inadimplência", ocorre quando os operadores ligam para o cliente devedor e os lembra do não pagamento de suas parcelas e a "telenegociação" que ocorre, por exemplo, nos bancos que financiam veículos (ou outro financiamento no qual sejam dados bens como garantia) na qual é negociada a regularização dos débitos para que o bem (garantia) não tenha que ser reavido pelo credor Teófilo (2006) apud Rocha (2010).

Quando terminam as alternativas de cobrança, iniciam-se as ações de recuperação de crédito, no qual as principais são as vias administrativa ou judicial. $\mathrm{Na}$ via administrativa realizada pela própria instituição fornecedora do crédito ou por empresa terceirizada contratada para esse fim a negociação é mais amena, já a negociação por vias judiciais normalmente é resultado de um impasse entre a instituição credora e o devedor.

O Serviço brasileiro de apoio às micro e pequenas empresas SEBRAE (2007) apud Rocha (2010). em estudo realizado em 2007 propõe algumas normas para se obter êxito no processo de recuperação de dívidas:

i. Cobrança instantânea: quanto mais rápida e eficaz a cobrança, menos será a dívida. Portanto, deve ser iniciada o prazo de três a dez dias de atraso no pagamento, tornando mais eficaz a recuperação do crédito e reduzindo os índices de inadimplência;

ii. Cobrança tradicional prévia: cobrança tradicional é aquela iniciada habitualmente após 30 dias de atraso no pagamento, por equipes treinadas para esse tipo de cobrança e que respeitem as normas contidas no Código de Defesa do Consumidor;

iii. Os títulos ou débitos protestados, ou seja, aqueles intimados pelo cartório e não pagos pelos devedores no prazo legal, são automaticamente comunicados para todos os cadastros de proteção ao crédito e sem qualquer despesa para os credores;

iv. A utilização de protesto é eficiente tendo em vista sua legalidade, agilidade, eficácia e não tem custos adicionais para o credor, não é coercitivo e não causa constrangimentos, assim evita conflitos com o Código de Defesa do Consumidor.

\section{MATERIAIS E MÉTODOS}

O estudo foi desenvolvido a partir da análise de uma amostra de cadastros de pessoas físicas (com renda mínima comprovada de $\mathrm{R} \$ 2.000,00)$ de uma instituição financeira em um município da região metropolitana de Fortaleza no ano de 2014. Estimou-se um modelo de previsão de probabilidade de inadimplência dada as características individuais de cada cliente como renda, idade, sexo, estado civil, grau de instrução, tempo de conta, entre outros. O modelo foi construído com base na metodologia de Lima (2004) e teve como principal objetivo captar relações significantes entre a variável dependente (probabilidade de inadimplência) e as variáveis explicativas (estado civil, tempo de conta, grau de instrução, idade e sexo):

$\widehat{P}_{t}=\frac{\exp \left(\delta_{1}+\delta_{2} X_{2 t}+\delta_{3} X_{3 t}+\delta_{4} X_{4 t} \delta_{5} X_{5 t}+\delta_{6} X_{6 t}\right)}{1+\exp \left(\delta_{1}+\delta_{2} X_{2 t}+\delta_{3} X_{3 t}+\delta_{4} X_{4 t} \delta_{5} X_{5 t}+\delta_{6} X_{6 t}\right)}$

Onde: $\widehat{P}_{t}=$ probabilidade de inadimplência; $\delta_{1}, \delta_{2}, \delta_{3}, \delta_{4}, \delta_{5}, \delta_{6}=$ parâmetros do modelo calculados pelo software econométrico Eviews 6.0; $X_{2 t}=$ Dummy (variáveis qualitativas) de identificação de solteiros (assumindo 1 se o indivíduo é solteiro e 0 caso contrário); $X_{3 t}=$ tempo de conta; $X_{4 t}=$ Dummy (variáveis qualitativas) de identificação de grau de instrução superior (assumindo 1 se tem curso superior e 0 caso contrário); $X_{5 t}=$ idade do indivíduo (em anos completos); $X_{6 t}=$ Dummy (variáveis qualitativas) de identificação de sexo (assumindo 1 se o indivíduo é do sexo masculino e 0 caso contrário).

\section{RESULTADOS E DISCUSSÕES}

Apresentam-se as características sociais e econômicas de uma carteira de clientes Pessoa Física de uma agência bancária em um município da região metropolitana de Fortaleza no ano de 2014.

\section{Características Socioeconômicas}

a) Sexo: Dos clientes da amostra estudada, 55,5\% são do sexo masculino e $44,5 \%$ do sexo feminino. Semelhante resultado foi obtido por Lima (2004) no seu trabalho sobre inadimplência no Município de Fortaleza. O Instituto de Pesquisa Econômica Aplicada (IPEA) realizou uma pesquisa em 2010 sobre "Sistema de Indicadores de Percepção Social (SIPIS) sobre bancos: exclusão e serviços" e concluiu que quase $40 \%$ dos brasileiros estão excluídos do sistema bancário. A pesquisa também concluiu que os homens com conta em bancos representam $56 \%$ contra $44 \%$ das mulheres, confirmando assim que ambos os sexos participam ativamente das Instituições Financeiras Brasileiras.

Não há porque associar maiores ou menores riscos de inadimplência ao indivíduo em virtude de seu sexo. Note-se que esse fato é bastante diferente do 
Tabela 1: Distribuição absoluta e relativa dos clientes de uma Instituição Bancária segundo gênero em um município da região metropolitana de Fortaleza - CE - 2014

\begin{tabular}{c|c|c}
\multirow{2}{*}{ Gênero } & \multicolumn{2}{|c}{ Clientes } \\
& Freq. Absoluta & Freq. Relativa (\%) \\
\hline Masculino & 107 & 55,5 \\
Feminino & 86 & 44,5 \\
\hline Total & $\mathbf{1 9 3}$ & $\mathbf{1 0 0 , 0}$ \\
& Fonte: Resultados da Pesquisa.
\end{tabular}

caso das seguradoras, relativo ao seguro de automóvel, onde, pela definição do perfil do segurado, em geral, o risco de sinistro associado a indivíduos do sexo masculino é maior (LIMA, 2004).

b) Faixa Etária: As informações apresentadas na tabela 2 mostram que $48,7 \%$ dos clientes têm idade entre 31 e 50 anos, sendo importante enfatizar a participação representativa de $39,3 \%$ com mais de 50 anos. A média de idade dos clientes é de 47 anos com mínimo de 19 anos e máximo de 87 anos. Espera-se que a idade esteja relacionada negativamente com a probabilidade de inadimplência, pois se pressupõe que os clientes com mais idade tenham mais responsabilidades nos assuntos referentes ao sistema bancário.

Tabela 2: Distribuição absoluta e relativa dos clientes de uma Instituição Bancária segundo gênero em um município da região metropolitana de Fortaleza - CE - 2014

\begin{tabular}{c|c|c}
\multirow{2}{*}{ Faixa etária } & \multicolumn{2}{|c}{ Clientes } \\
& Freq. Absoluta & Freq. Relativa (\%) \\
\hline Menos de 20 anos & 4 & 2,2 \\
$20 \leq$ idade $\leq 30$ & 19 & 9,8 \\
$31 \leq$ idade $\leq 50$ & 94 & 48,7 \\
Mais de 50 anos & 76 & 39,3 \\
\hline Total & $\mathbf{1 9 3}$ & $\mathbf{1 0 0 , 0}$
\end{tabular}

Fonte: Resultados da Pesquisa

Analisando a participação dos jovens (até 30 anos de idade) na amostra estudada, observa-se que apenas $9,8 \%$ dos clientes são jovens. Confirmando a pesquisa realizada em 24 países, inclusive no Brasil, pela TNS Research sobre Jovens e Conta Bancária no ano de 2010, no qual dos jovens brasileiros entrevistados, cerca de 1 milhão e 500 mil, apenas $20 \%$ têm sua renda proveniente do próprio trabalho, enquanto $80 \%$ têm nos pais a única ou principal fonte de renda. Dessa forma, a maioria dos jovens não possui conta bancária, pois grande parte não trabalha e ainda mora com os pais

c) Grau de Instrução: Os dados da tabela 3 expõem que, dos clientes selecionados, $56,9 \%$ possuem o Ensino Médio Completo e 42,7\%, o Ensino Superior Completo. Espera-se que clientes com maior nível educacional estejam associados à menor probabilidade de inadimplência, pois estes possuem uma maior facilidade para entender os produtos oferecidos e os termos financeiros utilizados pelos bancos.

O alto grau de capital humano ajuda a explicar porque alguns países são tão ricos e prósperos, pois estes investem bastante em educação. De acordo com (BARROS; HENRIQUES; MENDONÇA, 2000), a relação entre o nível de escolaridade média de uma sociedade e a intensidade da desigualdade educacional pode ser genericamente representada por uma curva com formato em " $U$ " invertido. Assim, quando o nível de escolaridade média de um país é de pequeno porte, a desigualdade tende a ser reduzida. Já quando aumentamos o nível de escolaridade de uma sociedade, constitui-se um instrumento essencial para reduzir a desigualdade salarial, confirmando que a educação ainda é o melhor caminho para se melhorar de vida.

Tabela 3: Distribuição absoluta e relativa dos clientes de uma Instituição Bancária segundo gênero em um município da região metropolitana de Fortaleza - CE - 2014

\begin{tabular}{c|c|c} 
Grau de & \multicolumn{2}{|c}{ Clientes } \\
instrução & Freq. Absoluta & Freq. Relativa (\%) \\
\hline Primeiro grau & 1 & 0,4 \\
Ensino medio & 110 & 56,9 \\
Ensino superior & 82 & 42,7 \\
\hline Total & $\mathbf{1 9 3}$ & $\mathbf{1 0 0 , 0}$
\end{tabular}

Fonte: Resultados da Pesquisa.

Muitos estudos mostram a importância da educação para o bem-estar de um país. Langoni (1973) apud Coutinho (2005) foi um dos primeiros economistas a ressaltar a importância da educação e enfatizar que um dos principais problemas sociais no Brasil decorre do baixo nível da educação e da sua má distribuição.

d) Principal Ocupação: A principal ocupação dos clientes selecionados nesta pesquisa é a área administrativa, 53,3\%, a qual engloba trabalhos como: administrador de empresas, contadores, economistas, assistentes e auxiliares administrativos, todos 
indispensáveis para uma gestão eficiente de qualquer empresa, independente do ramo trabalhado. Explica-se a concentração de profissionais nesta área devido aos setores que mais empregam no município estudado que são serviços, indústria e agropecuária, respectivamente, de acordo com o último censo do ((IBGE), 2010).

A tabela 4 mostra que as principais ocupações estão distribuídas nas seguintes áreas: $21,7 \%$ são professores, $9,3 \%$ são militares, $6,7 \%$ são comerciantes e também aposentados e pensionistas e 2,3\% são da área da saúde (auxiliar de enfermagem, enfermeiros, fisioterapeutas e médicos).

Tabela 4: Distribuição absoluta e relativa dos clientes de uma Instituição Bancária segundo gênero em um município da região metropolitana de Fortaleza - CE - 2014

\begin{tabular}{c|c|c} 
Principal & \multicolumn{2}{|c}{ Clientes } \\
Ocupação & Fr. Absoluta & Fr. Relativa (\%) \\
\hline Apos./Pensionistas & 79 & 40,9 \\
Área administrativa & 11 & 5,6 \\
Área da saúde & 98 & 50,7 \\
Comerciante & 98 & 50,7 \\
Militar & 98 & 50,7 \\
Professor & 5 & 2,8 \\
\hline Total & $\mathbf{1 9 3}$ & $\mathbf{1 0 0 , 0}$
\end{tabular}

e) Estado Civil: Em relação ao estado civil, tem-se que 50,7\% são solteiros, 40,9\% são casados, 5,6\% divorciados e $2,8 \%$ são viúvos. Pesquisas apontam que há uma tendência para casamentos tardios, pois principalmente as mulheres preferem dedicarse a carreira e os estudos para posteriormente pensar em montar uma família. A estabilização profissional e consequentemente a financeira, antigamente almejado muito mais por homens, são as principais razões para o adiamento do matrimônio.

De acordo com Lima (2004), os clientes casados recorrem mais ao crédito porque têm maiores responsabilidades, como casa e filhos. Mas uma pesquisa realizada pela National Bureau of Economic Research, no ano de 2011, constatou que os casados poupam bem mais que os solteiros, pois estes gastam muito com supérfluos enquanto que os casados saem menos de casa.

Um estudo elaborado pelo pesquisador do Centro de Pesquisa de Recursos Humanos, Jay Zagorsky, da Universidade do Estado de Ohio, no ano de 2007, constatou que o casamento faz bem para as finanças pessoais. Avaliou-se a situação financeira
Tabela 5: Distribuição absoluta e relativa dos clientes de uma Instituição Bancária segundo gênero em um município da região metropolitana de Fortaleza - CE - 2014

\begin{tabular}{c|c|c} 
Estado Civil & \multicolumn{2}{|c}{ Clientes } \\
& Freq. Absoluta & Freq. Relativa (\%) \\
\hline Casado & 79 & 40,9 \\
Divorciado & 11 & 5,6 \\
Solteiro & 98 & 50,7 \\
Viúvo & 5 & 2,8 \\
\hline Total & $\mathbf{1 9 3}$ & $\mathbf{1 0 0 , 0}$ \\
& \multicolumn{2}{|c}{}
\end{tabular}

e o estado civil de um grupo de quase dez mil pessoas durante 15 anos. Concluiu que os casados possuem patrimônio duas vezes maior que os solteiros, pois os casados não trabalham apenas para si, mas para o bem da família.

f) Renda: Os dados da tabela 6 revelam que $59 \%$ dos clientes têm renda mensal maior que cinco salários mínimos ( $\mathrm{R} \$ 3.620,00)$, utilizando o salário mínimo no valor de $\mathrm{R} \$ 724,00$. Este resultado está diretamente ligado a principal ocupação dos clientes estudados que foi a área administrativa. A quantidade de clientes com renda maior que cinco salários mínimos é explicada pelo fato de profissionais como administradores, contadores e economistas possuírem o salário inicial em torno de $\mathrm{R} \$ 2.000,00$ em micro e pequenas empresas, podendo este salário triplicar em grandes empresas, dependendo da experiência e capacitação continuada deste profissional.

A renda média dos indivíduos analisados é de aproximadamente $\mathrm{R} \$ 4.589,84$, sendo que entre os adimplentes esta média é de $\mathrm{R} \$ 3.542,12$ e entre os inadimplentes é de $\mathrm{R} \$ 1.047,71$. Espera-se que, quanto maior a renda, menor seja a inadimplência do cliente, pois este recorrerá menos ao crédito que os assalariados.

g) Tempo de Conta: O tempo de conta dos clientes da amostra estudada variou de 1 a 27 anos. Esse ponto é essencial na análise de crédito para o cliente, pois quanto mais tempo tiver a conta, mais credibilidade ele terá junto à instituição financeira.

Com base na tabela 7, nota-se que $53,8 \%$ possuem a conta há, no máximo, 5 anos, 32,6\% entre 6 e 16 anos e $13,6 \%$ possuem há mais de 17 anos. A média do tempo de conta dos clientes é de 9,6 anos com mínimo de 0 ano e máximo de 27 anos. Espera-se que o tempo de conta auxilie o cliente 
Tabela 6: Distribuição absoluta e relativa dos clientes de uma Instituição Bancária segundo gênero em um município da região metropolitana de Fortaleza - CE - 2014

\begin{tabular}{c|c|c} 
Renda & \multicolumn{2}{|c}{ Clientes } \\
& Freq. Absoluta & Freq. Relativa (\%) \\
\hline 1 Salário Míninimo $\leq \mathrm{R}<2$ Salários Mínimos & 2 & 1,3 \\
2 Salários Míninimos $\leq \mathrm{R}<$ 3 Salários Mínimos & 4 & 2,0 \\
3 Salários Míninimos $\leq \mathrm{R}<4$ Salários Mínimos & 30 & 15,5 \\
4 Salários Míninimos $\leq \mathrm{R}<5$ Salários Mínimos & 43 & 22,2 \\
$\geq$ 5 Salários Mínimos & 114 & 59,0 \\
\hline Total & $\mathbf{1 9 3}$ & $\mathbf{1 0 0 , 0}$
\end{tabular}

Tabela 7: Distribuição absoluta e relativa dos clientes de uma Instituição Bancária segundo gênero em um município da região metropolitana de Fortaleza - CE - 2014

\begin{tabular}{c|c|c} 
Tempo de & \multicolumn{2}{|c}{ Clientes } \\
Conta & Freq. Absoluta & Freq. Relativa (\%) \\
\hline Até 5 anos & 104 & 53,8 \\
$6 \leq$ idade $\leq 16$ & 63 & 32,6 \\
Mais de 17 anos & 26 & 13,6 \\
\hline Total & $\mathbf{1 9 3}$ & $\mathbf{1 0 0 , 0}$
\end{tabular}

Fonte: Resultados da Pesquisa.

a ser menos inadimplente, pois quanto maior o tempo de conta, mais credibilidade o cliente terá, e se a inadimplência acontecer, conseguirá resolver rapidamente devido ao bom relacionamento com o banco.

g) Inadimplência: Os dados da tabela 8 mostram que $62,17 \%$ dos clientes estão adimplentes e $37,83 \%$ inadimplentes. Mas devido a qual produto esses clientes encontram-se nessa situação? Os principais produtos são cartões de crédito, financiamentos de veículos, cheques especiais, cheques sem fundo e empréstimos bancários. Confirmaram-se os dados divulgados pela Serasa Experian de Inadimplência do Consumidor,que registrou crescimento de 4,8\% em abril de 2012, referente principalmente ao uso do cartão de crédito.

De acordo com o Brasil (2012), a inadimplência alcançou o maior patamar desde o ano 2000, pois no crédito para a compra de veículos chegou a $6,1 \%$ e nos financiamentos de faturas de cartão de crédito $29,49 \%$. Mesmo com o aumento da inadimplência, o governo continua praticando políticas monetárias expansivas, facilitando o acesso ao crédito pelos clientes e dificultando a quitação das contas já existentes.
Tabela 8: Distribuição absoluta e relativa dos clientes de uma Instituição Bancária segundo gênero em um município da região metropolitana de Fortaleza - CE - 2014

\begin{tabular}{c|c|c} 
Está & \multicolumn{2}{|c}{ Clientes } \\
Inadimplente? & Freq. Absoluta & Freq. Relativa (\%) \\
\hline SIM & 73 & 37,83 \\
NÃO & 120 & 62,17 \\
\hline Total & $\mathbf{1 9 3}$ & $\mathbf{1 0 0 , 0}$
\end{tabular}

Fonte: Resultados da Pesquisa.

\subsection{Modelo de Previsão de Inadimplência}

Com a utilização do software econométrico EViews na obtenção das estimativas dos parâmetros do modelo de previsão de inadimplência, o objetivo é identificar relações significantes entre a variável dependente (probabilidade de inadimplência) e as variáveis explicativas (estado civil, tempo de conta, grau de instrução, idade, sexo e renda).

A tabela 9 apresenta o valor de $\mathrm{R}$, que é o coeficiente de correlação que mostra o grau de associação entre as variáveis dependentes e explicativas. Quanto mais próximo do índice/valor 1, mais o coeficiente mostra que existe uma relação entre as variáveis de estudo. O coeficiente de correlação do modelo de previsão de inadimplência foi de $\mathrm{R}=0,89$, mostrando que existe uma forte relação entre as variáveis estudadas.

Para identificar um bom ajuste do modelo, analisase o $R^{2}$ que quanto mais próximo de 1 (um), melhor a relação entre as variáveis. O $R^{2}$ é o poder explicativo do modelo de regressão e mostra que $72 \%$ da variabilidade encontrada na variável dependente é explicada pelas variáveis independentes.

O erro padrão de estimativa é outra medida de precisão da previsão, representando o desvio-padrão em torno da reta de regressão. Quanto menor o erro padrão da estimativa, melhor o modelo estimado. 
ANÁLISE DA INADIMPLÊNCIA BANCÁRIA: UM ESTUDO DE CASO DA REGIÃO METROPOLITANA DE FORTALEZA

Tabela 9: Resumo do Modelo de Previsão de Inadimplência

\begin{tabular}{c|ccc} 
& $\mathbf{R}$ & $R^{2}$ & Erro Padrão \\
\hline Modelo & 0,89 & 0,72 & 0,38 \\
\hline
\end{tabular}

Fonte: Resultados da Pesquisa.

A tabela 10 mostra os resultados dos coeficientes do modelo de previsão de inadimplência obtidos pelo programa estatístico utilizado. Os coeficientes mais confiáveis são as variáveis tempo de conta, idade e renda, pois estatisticamente os coeficientes serão mais confiáveis quanto menores forem seus desvios-padrão ( é uma medida de dispersão. Ele dá uma idéia de como os valores de uma amostra estão dispersos em relação à média. Quanto maior o desvio padrão, maior é a dispersão dos valores em relação à média. Um desvio padrão igual a zero indica que todos os valores são iguais à media). Confirmou-se a expectativa de que a inadimplência tem uma forte relação com o tempo de conta, pois quanto mais antiga for a conta, maior a probabilidade de o banco oferecer produtos e serviços, em virtude de um maior nível de confiança baseado no tempo de relacionamento.

Quanto à idade, pressupõe-se que, quanto mais velho, maior a responsabilidade em honrar compromissos assumidos. O grau de instrução facilita o entendimento das explicações dos serviços bancários, demonstrando que as pessoas mais instruídas podem ficar inadimplentes, mas não devido à falta de informação, e sim ao descontrole financeiro ou qualquer problema de outra natureza. E na análise da renda, espera-se que quanto maior sua renda, menos inadimplente o cliente seja, pois com uma renda mais abastada pode-se obter uma melhor organização de suas finanças, resultando assim nos pagamentos de dívidas contraídas no período correto.

Com base nos coeficientes da tabela 10 tem-se o modelo de previsão de inadimplência $(\mathrm{P}): P=0,345+$ 0,031* EstadoCivil - 0,093* TempoDeConta $0,063 *$ GrauDeInstrucao $+0,082 *$ Idade $+0,33 *$ Sexo - 0,00072*Renda

O valor de 0,345 é o valor esperado para a previsão de inadimplência quando não houver a existência das variáveis explicativas (estado civil, tempo de conta, instrução, idade, sexo e renda). Há uma diminuição prevista na inadimplência para o aumento de uma unidade no tempo de conta. Nesse caso, a diminuição prevista da inadimplência por aumento de uma unidade no tempo de conta é de 0,093.

Já na variável explicativa idade, ocorrerá um aumento na inadimplência para o aumento de uma unidade da idade. $\mathrm{O}$ aumento previsto da inadimplência por aumento de uma unidade na idade é de 0,082. Concluindo que, quanto maior a idade, maior a probabilidade de inadimplência, pode-se levar em consideração que isso ocorra devido às responsabilidades que as pessoas assumem quando ficam mais velhas, como casamentos, filhos e compra da casa própria.

$\mathrm{Na}$ variável renda, haverá uma diminuição na inadimplência para o aumento de renda no valor de 0,00072 , confirmando que, quanto maior a renda do cliente, menor a probabilidade de sua inadimplência, pois este cliente pode organizar-se melhor e pagar suas contas no período hábil.

As variáveis estado civil, grau de instrução e sexo são variáveis qualitativas e não numéricas como o tempo de conta, idade e renda, por isso suas interpretações são diferentes. Em relação ao estado civil (1 = solteiro, $0=$ caso contrário $)$, grau de instrução $(1=$ nível superior, $0=$ caso contrário $)$ e sexo $(1=$ masculino, $0=$ caso contrário), para ilustrarmos o procedimento utilizado, foram apresentadas duas situações, e em ambas, utilizado o sexo masculino por escolha aleatória, pois o modelo não demonstrou significativas diferenças em relação ao sexo do cliente:

a) Exemplo 1: cliente solteiro, com nível superior, sexo masculino, 15 anos de conta, 40 anos de idade e renda de $\mathrm{R} \$ 6.000,00$. Com base no modelo construído, temos que:

$P=0,345+0,031 *$ EstadoCivil $-0,093 *$ TempoDeConta - 0,063* GrauDeInstruo + $0,082 *$ Idade $+0,33 *$ Sexo $-0,00072 *$ Renda $P=0,345+0,031 * 1-0,093 *$ TempoDeConta - 0,063*1+0,082* Idade $+0,33 * 1-0,00072 *$ Renda $P=0,345+0,031-0,093 *$ TempoDeConta$0,063+0,082 *$ Idade $+0,33-0,00072 *$ Renda $P=0,643-0,093 *$ TempoDeConta $+0,082 *$ Idade $0,00072 *$ Renda

$P=0,643-0,093.15+0,082.40-0,00072.6000$

$P=0,643-1,395+3,28-4,32=-1,792$

Calculando a probabilidade de inadimplência temos:

$\widehat{P}_{t}=\frac{\exp \left(\delta_{1}+\delta_{2} X_{2 t}+\delta_{3} X_{3 t}+\delta_{4} X_{4 t} \delta_{5} X_{5 t}+\delta_{6} X_{6 t}+\delta_{7} X_{7 t}\right)}{1+\exp \left(\delta_{1}+\delta_{2} X_{2 t}+\delta_{3} X_{3 t}+\delta_{4} X_{4 t} \delta_{5} X_{5 t}+\delta_{6} X_{6 t}+\delta_{7} X_{7 t}\right)}$

$$
\widehat{P}_{t}=\frac{\exp (-1,792)}{1+\exp (-1,792)}=\frac{0,1666}{1,1666}=0,1428=14,28 \%
$$




\begin{tabular}{c|ccc} 
Variável & Coeficiente & Desvio-padrão & Significância \\
\hline C & 0,345 & 0,018 & 0,587 \\
Estado Civil & 0,031 & 0,065 & 0,929 \\
Tempo de Conta & $-0,093$ & 0,001 & 0,306 \\
Grau de Instrução & $-0,063$ & 0,015 & 0,636 \\
Idade & 0,082 & 0,004 & 0,610 \\
Sexo & 0,33 & 0,064 & 0,292 \\
Renda & $-0,00072$ & 0,006 & 0,411 \\
\hline
\end{tabular}

Fonte: Resultados da Pesquisa.

A probabilidade de inadimplência associada a esse cliente, em uma escala de 0 a $10 \%$, na qual quanto mais próximo de 0 , menor a probabilidade de inadimplência, é de 14,28\%. Com base no modelo estimado, conclui-se que um cliente com nível superior, maior tempo de conta, renda mais elevada, idade maior que 30 anos e solteiro, tenha uma menor probabilidade de inadimplência, pois é um cliente mais esclarecido em relação aos produtos e procedimentos bancários; em razão do maior tempo de conta, possui um melhor relacionamento e consegue uma taxa de juros mais baixa; por possuir maior renda, tem maior capacidade de pagamento; e por ter mais idade, é mais consciente de suas responsabilidades perante o setor bancário.

b) Exemplo 2: cliente não solteiro, sem nível superior, sexo masculino, 2 anos de conta, 25 anos de idade e renda de $\mathrm{R} \$ 622,00$. Com base no modelo construído, temos que:

$P=0,345+0,031 *$ EstadoCivil $-0,093 *$ TempoDeConta-0,063*GrauDeInstrucao+ $0,082 *$ Idade $+0,33 *$ Sexo $-0,00072 *$ Renda $P=0,345+0,031 * 0-0,093 *$ TempoDeConta $-0,063 * 0+0,082 *$ Idade $+0,33 * 1-0,00072 *$ Renda $P=0,345-0,093 *$ TempoDeConta $+0,082 *$ Idade $+0,33-0,00072 *$ Renda

$P=0,675-0,093 *$ TempoDeConta $+0,082 *$ Idade $-0,00072 *$ Renda $P=0,675-0,093 * 2+0,082 * 25-0,00072 * 622$ $P=0,675-0,186+2,05-0,44=2,099$

Calculando a probabilidade de inadimplência temos:

$\widehat{P}_{t}=\frac{\exp \left(\delta_{1}+\delta_{2} X_{2 t}+\delta_{3} X_{3 t}+\delta_{4} X_{4 t} \delta_{5} X_{5 t}+\delta_{6} X_{6 t}\right)}{1+\exp \left(\delta_{1}+\delta_{2} X_{2 t}+\delta_{3} X_{3 t}+\delta_{4} X_{4 t} \delta_{5} X_{5 t}+\delta_{6} X_{6 t}\right)}$

$$
\widehat{P}_{t}=\frac{\exp (2,099)}{1+\exp (2,099)}=\frac{8,1580}{9,1580}=0,8908=89,08 \%
$$

A probabilidade de inadimplência associada a esse cliente, em uma escala de 0 a $100 \%$, na qual quanto mais próximo de 0 , menor a probabilidade de inadimplência, é de $89,08 \%$. Com base no modelo estimado, conclui-se que um cliente sem nível superior, menor tempo de conta, renda mais baixa, idade menor que 30 anos e não solteiro, tenha uma maior probabilidade de inadimplência, pois é um cliente menos esclarecido em relação aos produtos e procedimentos bancários; possui menos tempo de conta, dificultando assim o relacionamento com o banco, pois este ainda não poderá se basear no histórico do cliente; possui menor renda e por isso menor capacidade de pagamento; e é muito jovem e com maior probabilidade de ter gastos desnecessários, prejudicando assim a sua capacidade de honrar seus compromissos financeiros.

\section{CONSIDERAÇÕES FINAIS}

A principal função dos bancos é conceder créditos, mas estes créditos podem não ser pagos no tempo estipulado por inúmeras razões, por isso a busca incessante do setor bancário em tentar identificar antes de conceder o crédito o cliente que terá a maior probabilidade de não honrar os compromissos assumidos com a instituição.

$\mathrm{O}$ crescimento dos processos de gestão de risco tem trazido grandes contribuições de técnicas estatísticas, matemáticas, econométricas e computacionais, auxiliando ao gestor de crédito uma maior previsão quanto à inadimplência. Por conta disso, da necessidade dessa previsão, este trabalho teve como principal objetivo analisar os principais fatores que determinam a inadimplência de clientes de um banco comercial em um mu- 
nicípio da região metropolitana de Fortaleza/Ceará no ano de 2014.

O modelo foi construído com 193 cadastros de pessoa física, observando as características individuais como idade, sexo, renda, grau de instrução, tempo de conta, estado civil e principal ocupação. Com base nos resultados do estudo, concluiu-se que o sexo masculino $(55,5 \%)$ e feminino $(44,5 \%)$ possui participações semelhantes no setor bancário, a idade média dos clientes é de 47 anos com mínimo de 19 anos e máximo de 87 anos, a escolaridade concentra-se $56,9 \%$ no ensino médio completo e $42,7 \%$ ensino superior completo, e em relação ao estado civil têm-se que $50,7 \%$ dos clientes são solteiros e $40,9 \%$ são casados. A renda de $59 \%$ dos clientes da agência estudada é maior ou igual a cinco salários mínimos (R $\$ 3.620,00)$ e o tempo de conta dos clientes de até 5 anos é de 53,8\%.

Os dados da amostra estudada também mostram que $62,17 \%$ dos clientes estão adimplentes e 37,83\% inadimplentes. Os principais produtos responsáveis pela inadimplência são cartões de crédito, financiamentos de veículos, cheques especiais e empréstimos bancários.

O modelo construído teve como objetivo identificar relações significantes entre a variável dependente (probabilidade de inadimplência) e as variáveis explicativas (estado civil, tempo de conta, grau de instrução, idade, sexo e renda). Os coeficientes mais confiáveis mostrados pelo modelo foram as variáveis tempo de conta, idade, grau de instrução e renda, pois estes mostram com maior precisão as características mais comuns dos possíveis não pagadores do crédito concedido no período estipulado por ambas as partes envolvidas. Confirmando a primeira hipótese deste trabalho que a inadimplência independe do sexo do cliente, pois esta variável não se mostrou confiável.

Os coeficientes mostram ainda que, quanto maior o tempo de conta do cliente, maior a probabilidade de um relacionamento mais confiável entre ele e o banco, facilitando assim a concessão de empréstimos ou financiamentos e também uma possível negociação para o pagamento de dívidas que possam vir a ser contraídas.

Em relação à idade e o estado civil, pode-se pressupor que, quanto maior a idade, maior a responsabilidade e, dessa forma, menos dívidas. E que os clientes casados sejam menos inadimplentes devido a sua maior responsabilidade. Porém neste ponto as hipóteses do trabalho foram contrariadas, pois o resultado obtido pelo modelo foi que quanto maior a idade, e o cliente sendo casado, maior a probabilidade de inadimplência, podendo-se explicar este fato devido às responsabilidades que as pessoas assumem quando ficam mais velhas, como casamentos, filhos e compra da casa própria.
Já o grau de instrução e a renda foram diretamente ligados: quanto mais anos de estudos, maior a probabilidade de obter um melhor salário e assim, possivelmente, ser menos inadimplente, confirmando assim as hipóteses de que quanto maior o grau de instrução e renda, menos inadimplente seria o cliente.

Os resultados obtidos pelo modelo utilizado demonstraram que não houve relações significantes, como esperado, entre todas as variáveis estudadas, porém acredita-se que os resultados alcançados neste trabalho podem ser aprofundados através de estudos posteriores em outras cidades e em outros bancos, para se alcançar novas e, quem sabe, mais específicas conclusões quanto à relação entre as principais variáveis utilizadas na gerência de risco de um cliente bancário, auxiliando assim a detecção de maior ou menor probabilidade de inadimplência desses clientes.

\section{REFERÊNCIAS}

BARROS, R. P.; HENRIQUES, R.; MENDONÇA, R. S. P. Pelo fim das décadas perdidas : educação e desenvolvimento sustentado no brasil. Instituto de Pesquisa Econômica Aplicada, p. p. 405-423, 2000.

BLATT, A. Avaliação de Risco e Decisão de Crédito. : Nobel, 1999.

BRASIL, B. C. do. Relatório de Estabilidade Financeira. 2011. Disponível em: <http//: www.bacen.gov.br>

. Inadimplência do consumidor tem a maior alta para abril em dez anos. 2012. Disponível em: <http://migre.me/wqLMF>

CHANG, E.; GUERRA, S.; LIMA, E.; TABAK, B. The stability-concentration relationship in the brazilian banking system. Journal of International Financial Markets, Institutions and Money, v. 18, n. 4, p. 388-397, Outubro 2008.

CIHÁK, M. Introduction to applied stress testing. : Washington: International Monetary Fund, 2007.

COUTINHO, J. C. O mercado de trabalho e a realidade econômica brasileira: um estudo de caso da atividade econômica da comunidade do loteamento Jardim Zanellato em São José. Dissertação (Mestrado) - Universidade Federal de Santa Catarina (UFSC), Santa Catarina, 2005.

GONÇALVES, T. C. O Sistema Financeiro Brasileiro: Evolução do Crédito no Brasil Pós-Plano Real.

Dissertação (Mestrado) — Fundamentação Armando

Álvares Penteado, São Paulo, 2007. 
(IBGE), I. B. de geografia e E. Censo de 2010. 2010.

Disponível em: <http://censo2010.ibge.gov.br/>

LANARI, C. S.; JUNIOS, L. A. L. Classificando o risco de crédito através de rating: uma nova realidade para as instituições brasileiras. Dissertação (Mestrado) — Universidade Federal de Minas Gerais (UFMG), Minas Gerais, 2000.

LIMA, E. M. B. d. C. Análise de determinantes da inadimplência (pessoa física) tomadores de crédito: uma abordagem econométrica. Dissertação (Mestrado) — Universidade Federal do Ceará (UFC), 2004.

LUCCA, E. A cidadania e a inadimplência no Brasil. Disponível em: <www.bancohoje.com.br/artigo.asp? Artigo=696>

MAIA, A. do S. R. S. Inadimplência e Recuperação de crédito. Dissertação (Mestrado) - Universidade Federal do Rio Grande do Sul, Rio Grande do Sul, 2007.

MENDES, M. V. de A. A inadimplência e o ciclo de crédito no Brasil: uma análise com dados em painel. Dissertação (Mestrado) — Pontifícia Universiade Católica do Rio de Janeiro, Rio de Janeiro, 2013.

PIROLO, J. Uma proposta para criação de uma estrutura para cobrança de dívidas em instituições bancárias e comerciais. Dissertação (Mestrado) Universidade Federal de Santa Catarina (UFSC), 2003.

ROCHA, F. C. A Inadimplência de Créditos no setor bancário brasileiro: um estudo de caso. Dissertação (Mestrado) - Universidade Federal de Santa Catarina (UFSC), 2010.

SBICCA, A.; FLORIANI, V.; JUK, Y. Expansão do crédito no brasil e a vulnerabilidade do consumidor. Revista Economia e Tecnologia (RET), v. 8, n. 4, p. 05-16, Dezembro 2012.

SCHRICKEL, W. K. Análise de crédito: concessão e gerência de empréstimos. 4 ed.. ed. : Atlas, 1997.

SILVA, J. P. da. Gestão e Análise de Risco de Crédito. 8 ed.. ed. : Atlas, 1998. 